\title{
Maxillar implant-retained overdenture using CAD/CAM milled zirconia bar with PEKK sleeve: a case report
}

\author{
Jin-Seok Ju, Jin-Hyun Cho, Cheong-Hee Lee* \\ Department of Prosthodontics, School of Dentistry, Kyungpook National University, Daegu, Republic of Korea
}

The object of this case report is to introduce milled zirconia bar and PEKK female part made by CAD/CAM technology for bar attachment implant supported overdenture in maxillary edentulous patients. For over 2 years, in terms of function and esthetics, satisfactory result was obtained. Esthetically and functionally satisfactory results were obtained in periodic follow up check. (J Dent Rehabil Appl Sci 2017;33(4):307-13)

Key words: maxillary edenturous; milled zirconia bar; PEKK sleeve; implant supported overdenture

\begin{abstract}
서론
상악 무치악 환자의 보철수복에서 임플란트를 이용한 피개의치는 해부학적 요인, 경제적 요인에 의해서 계획 되는 경우가 있다. ${ }^{1}$ 의치에 적절한 유지력을 제공하고 환 자에게 심리적 안정감을 준다는 장점을 가지며, 발음, 심 미성 등의 측면에서 전통적인 총의치보다 높은 만족도를 보인다. ${ }^{2}$ 임플란트 피개의치는 지지형과 유지형으로 나 눌 수 있으며, 임플란트 지지형 피개의치의 경우, 상악에 서 4-6개의 임플란트를 식립하여 연결고정 후 피개의치 를 제작한 환자의 경과관찰에서, 높은 성공률과 환자 만 족도를 보고하였다. ${ }^{3,4}$ 임플란트 피개의치를 위해 사용되 는 어태치먼트는 임플란트사이의 연결 유무에 따라 연결 고정형과 개별유지형으로 나눌 수 있으며, ${ }^{5}$ 연결고정형인 바 어태치먼트는 개별유지형에 비해 높은 유지관리 능력 및 유지력에 대한 만족도를 보였다. ${ }^{6}$ 바 어태치먼트를 위 한 치과재료로는 주로 티타늄, 금합금 등이 사용되어져 왔다. 하지만, 금속을 이용한 바 어태치먼트 시스템은 심 미적으로 불리하며 환자에 따라 알러지 반응 등의 부적

*Correspondence to: Cheong-Hee Lee

Assistant Professor, Department of Prosthodontics, Kyungpook University Dental Hospital, 2175 Dalgubul-dero, Jung-gu, Daegu, 41904, Republic of Korea Tel: +82-53-600-7673, Fax: +82-53-427-0778, E-mail: chlee@knu.ac.kr Received: September 7, 2017/Last Revision: September 21, 2017/Accepted: September 22, 2017
\end{abstract}

절한 조직 반응을 일으킬 가능성이 있다. 또한, 전통적인 주조방법을 통한 제작과정에 많은 비용과 시간이 발생하 고, 주조과정에서의 수축, 납착과정에서의 오차가 발생 할 수 있다는 단점이 있다. 최근에 이러한 문제점들을 해 결하고자 $\mathrm{CAD} / \mathrm{CAM}$ 을 이용하여 바를 제작하는 방법 이 소개되어 활용되고 있다. 본 증례에서는 상악 완전 무 치악환자에서 CAD/CAM을 이용하여 지르코니아 바 어 태치먼트를 제작하였고, 바를 덮는 슬리브는 치과용 고 분자 물질인 PEKK를 이용하여 피개의치를 제작하였다. 주기적인 경과 관찰 결과 심미적, 기능적으로 만족할 만 한 결과를 얻었기에 이를 보고하는 바이다.

\section{증례보고}

\section{1. 환자 개요 및 구강 검사}

69세 남자 환자로 \#15, 14, 23, 24를 지대치로 하는 부 분 틀니를 제작하여 사용 중이었으나, 본원 내원 2개월 전, 지대치 \#14의 자연 발치로, 의치의 잦은 탈락과 저작

Copyright@ 2017 The Korean Academy of Stomatognathic Function and Occlusion. (c) It is identical to Creative Commons Non-Commercial License. 
시 불편감을 호소하였다. 구강내 시진과 파노라마 방사 선 검사상, 하악 치아들에 전반적인 치석이 관찰되었고, $\# 15,23,24$ 에 중등도 이상의 동요도와 골흡수, \#37에 치수 침범이 있는 충치가 관찰되었다. 상악 잔존치조골 은 전반적으로 중등도의 수평적 골흡수를 나타냈고, 상 악 양측 구치부에서부터 상악동 하연과 치조정사이의 거 리는 최소 $3 \mathrm{~mm}$ 정도로 관찰되었다. 악관절과 관련한 환 자의 불편사항은 없었고, 뇌졸중과 당뇨로 관련 약을 복 용 중이었다(Fig. 1).

\section{2. 치료계획}

하악의 경우, 전치부에서 방사선 사진상 상당량의 골 소실이 있었으나, 치아의 동요가 관찰되지 않았고, 심미 적인 측면 등에서 환자분의 불편감이 없었기 때문에, 하 악 전반적인 치석제거와 더불어 치주치료를 통해 유지하 기로 하였다. \#37 근관치료 후 단일 치아 수복 계획하였 다. 상악에서 현재 사용중인 부분틀니와 지대치의 유지 는 더이상 어렵다고 판단하여, 예후가 불량한 \#15, 23, 24 발치를 시행하였다. 환자분 경제적 사정으로 고정성 치료는 어렵다고 하였으며, 예전에 사용하던 틀니보다

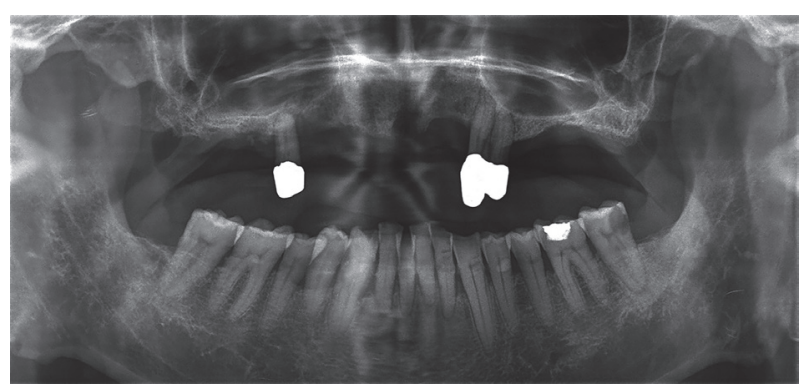

Fig. 1. Initial panoramic radiographic evaluation: Severe bone loss on maxillary residual ridge.
유지력과 저작력의 개선을 원하여 임플란트 피개의치 를 계획하였다. 하악의 치아가 모두 자연치임을 고려하 여 임플란트 6개 식립을 고려하였고, 의치를 유지하기 위 한 어태치먼트로는 연결고정형인 바를 사용하기로 하였 다. 바의 재료는 심미적 개선과 조직반응 개선 측면에서 유리한 지르코니아 바를 사용하기로 했고, 바를 덮는 슬 리브 부분은 치과용 고분자 물질인 PEKK (Poly-EtherKetone-Ketone; Pekkton ${ }^{\circledR}$ Cendres+Metaux SA, BielBienne, Switzerland)을 이용하여 제작하기로 하였다.

\section{3. 임플란트 식립 및 2차 수술}

상악 잔존치인 \#15, 23, 24 발치를 시행하였고, 발치 당일 임시총의치를 장착하였다. 발치 2개월 후 양측 상악 동 거상술을 시행하였다. 사용하던 임시총의치를 복제하 여 임플란트 수술용 방사선 스텐트 제작하여, 파노라마 방사선 사진과 치과용 콘빔전산화단층영상을 촬영하였 다. 상악동 거상술 6 개월 후 \#17, 15, 13, 23, 25, 27 부위 에 길이 $10 \mathrm{~mm}$, 직경 $4.0 \mathrm{~mm}$ 임플란트(Superline, Dentium, Seoul, Korea) 를 식립하였으며, 1차 수술 3개월 후, 2차 수술을 시행하였다(Fig. 2).

\section{4. 가공 지르코니아 바의 제작}

가공 지르코니아 바 제작을 위해 임플란트에 인상용 코핑을 연결한 후 픽업 인상을 채득하였다. 인상체에 아 날로그를 연결해 경석고 모형을 만든 후, 모형 상에서 교 합상, 교합제를 만들어 임시총의치를 참조하여 수직고경 과 중심위를 채득하였다. 이를 바탕으로 인공치 배열을 시행하여 납의치를 만들었다. 실리콘 지표를 제작하여 공간평가를 시행하였다. 모형의 아날로그에 스캔바디를 연결하여 탁상용 스캐너(Ceramill Map400, Amann Gir-
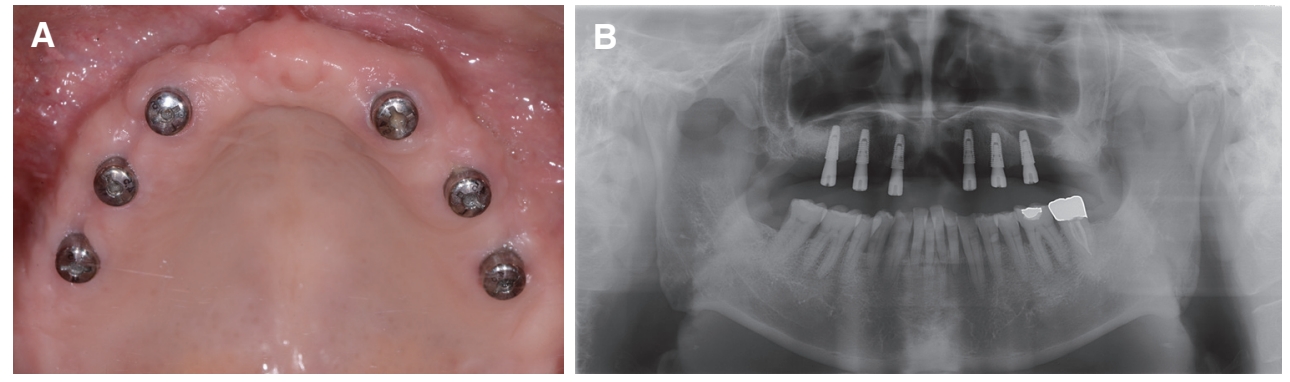

Fig. 2. Intraoral view (A) and panoramic radiograph (B) after implant placement. 
rbach AG, Koblach, Austria)로 모형과 임플란트에 대한 데이터를 얻은 후, 이를 바탕으로 프로그램 상에서 바 디 자인을 시행한 후에 지르코니아 블록을 밀링한다. ${ }^{6}$ Ceramill Mind \& Motion2 (Amann Girrbach AG, Koblach, Austria) 바의 완성 후 모형상에서 바의 적합도를 확인하 였다(Fig. 3).

\section{5. 가공 지르코니아 바의 장착 및 기능인상의 채득}

완성된 바를 환자 구강 내에 시적하여 적합도를 확인 하였다. 개인트레이를 이용하여 변연 형성 후, 바를 폴 리 비닐실록산 인상재로 픽업 인상을 인상을 채득하였다 (Fig. 4).

\section{6. 교합고경 채득 및 납의치 시적}

주모형상에서 기록상과 교합제를 제작한 후, 환자 구 강 내에 시적하여 적절한 교합 평면을 설정하고, 적절한 수직고경, 중심위를 채득하였다. 채득한 교합제에 치아 를 배열하여 납의치를 만들어 구강내에 시적하여, 구순 지지도 등 연조직에 대한 부분도 평가하였다. 수정, 확인 한 납의치에 실리콘 지표를 제작하였다(Fig. 5).

7. PEKK 이용하여 피개의치의 슬리브, 구개 밴드 제 작 및 최종 보철물 제작

가공 지르코니아 바를 연결한 주 모형을 스캔하여 바 를 덮는 슬리브를 디자인(Zirkonzhan.Modellier, Zirkon-
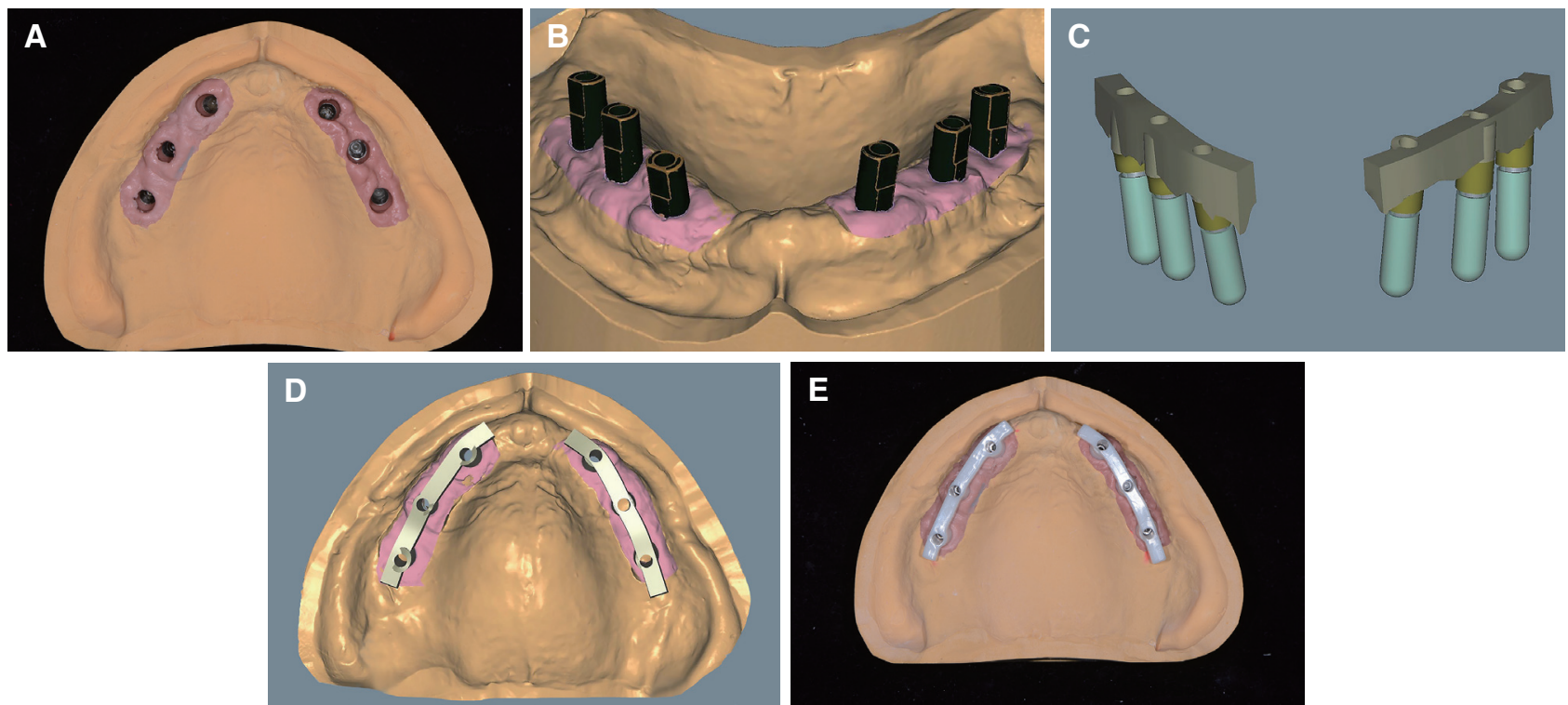

Fig. 3. Fabrication of milled zirconia bar with CAD/CAM. (A) Stone model, (B) Scanned model with scanbody, (C, D) Design of zirconia bar on CAD, (E) Trial of milled zirconia bar on stone model.
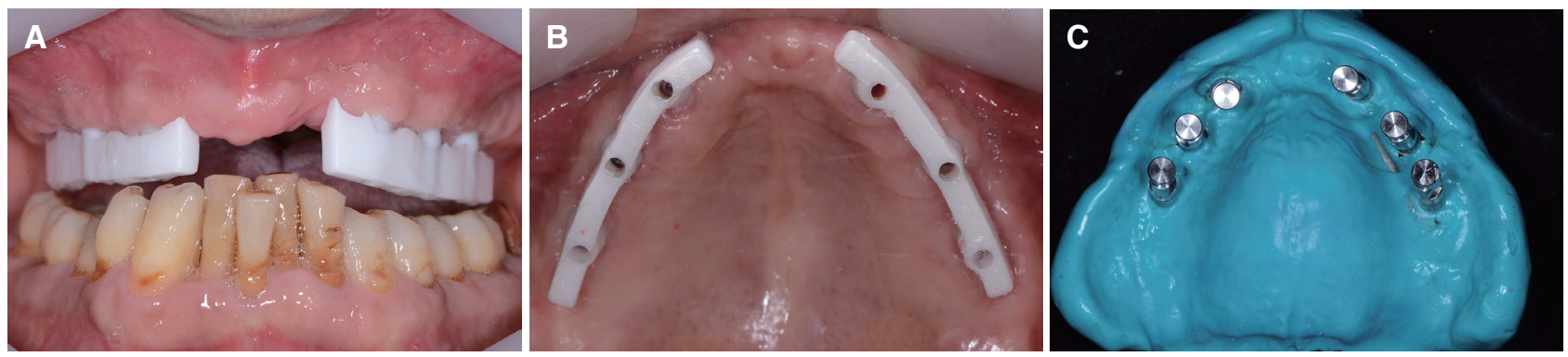

Fig. 4. Milled zirconia bar try-in. (A) Front view, (B) Occlusal view, (C) Pick-up impression. 

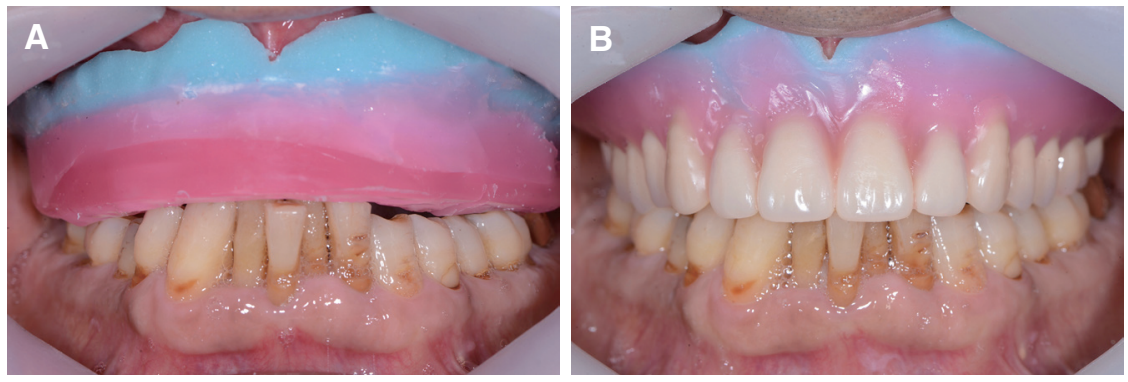

Fig. 5. Wax rim (A) and Wax denture (B) try-in.
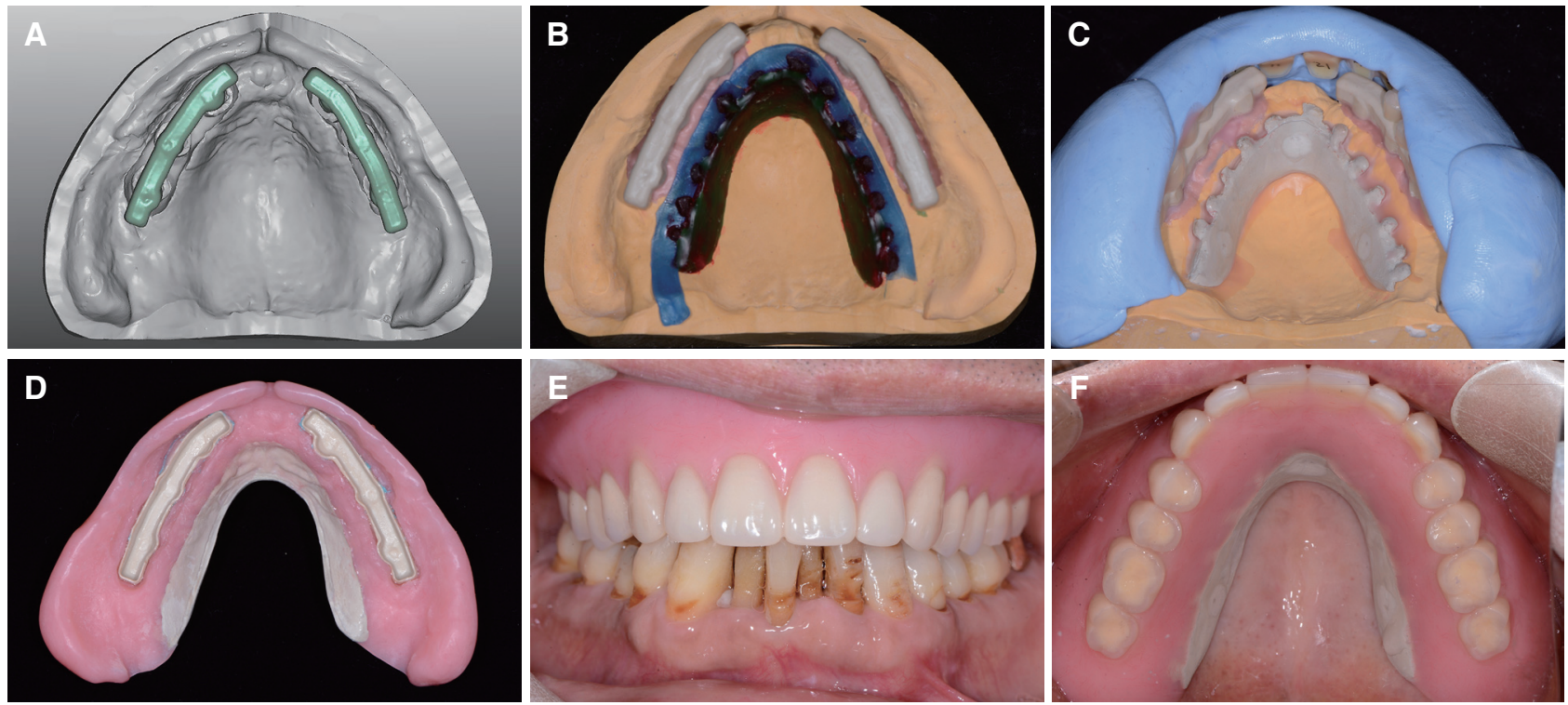

Fig. 6. Design \& fabrication of spra-structure of milled zirconia bar with CAD/CAM. (A) Design using Zirkonzhan Modellier, (B) Patal band wax up, (C) Putty index try-in, (D) Final prosthesis, (E) Delivery of overdenture, front view, (F) Occlusal view.

zahn GmbH, Bruneck, Italy)하여 PEKK로 제작하였다. 이렇게 제작된 슬리브와 구개부 납형 형성 후 프레스 방 법으로 제작한 구개 밴드를 자가중합레진(Pattern resin LS, GC America Inc, Alsip, USA)으로 연결하고, 구강 내에 시적하여 적합도를 확인하였다. 제작해 놓은 실리 콘 지표를 이용하여 슬리브와 구개밴드와 치아 사이의 공간을 왁스로 채운 후, 교합기상에서 교합조정하고, 매 몰 후 의치 중합 시행하여 의치를 완성하였다. 의치는 구 개 부위가 열려 있는 U자 형태로 제작하였다. 완성된 피 개의치를 구강 내에서 압력지시제를 이용하여 내면 적합 도를 검사한 후, 교합 조정을 하였다(Fig. 6). 정기적인 검 진에서 기능과 심미측면에서 만족할 만한 결과를 얻을 수 있었다(Fig. 7).

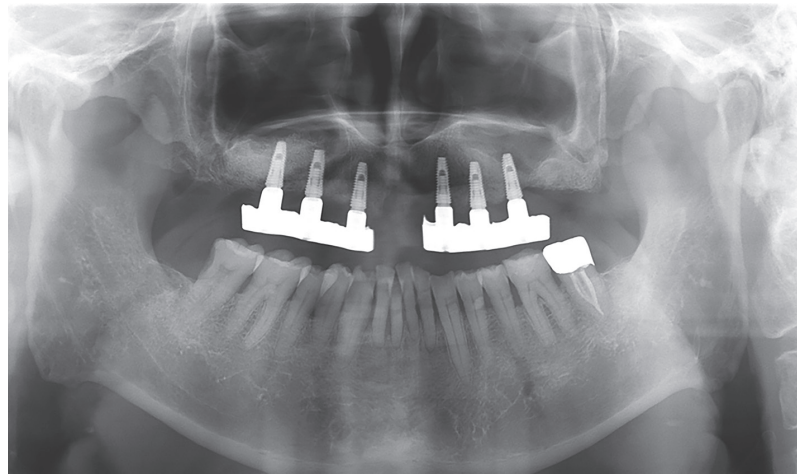

Fig. 7. Panoramic view after 2 years final prosthesis placement: showing stable bone level of peri-implants. 


\section{고찰}

상악 무치악 환자에서 전통적인 치료방법은 총의치를 이용하여 환자의 기능, 심미성 회복을 해주는 것이다. ${ }^{7}$ 하 지만, 무치악환자에서 총의치 치료는 시간의 경과에 따 른 점진적인 골소실이 관찰되며, 저작력, 저작 효율이 $1 / 4$ 가량 감소하고, 심리적 만족도가 감소한다는 한계가 있다. ${ }^{8}$ 근래에 소수의 임플란트를 이용한 임플란트 지지 피개의치의 안정적인 결과들이 보고되면서, 저작력, 교 합, 발음의 향상 등 환자의 만족도를 높일 수 있는 예측 가능한 치료법의 하나로 인식되고 있다. ${ }^{9,10}$

임플란트 피개의치의 어태치먼트 시스템은 임플란트 사이의 연결여부에 따라 연결고정형, 개별유지형으로 나 눌수 있다. 상악 피개의치의 경우, 골의 질과 힘의 방향성 측면을 고려하여 연결 고정형을 선택하는 것이 권장되고 있고, 최소한의 임플란트 수는 최소 4개, 그리고 전후방 임플란트 사이 거리를 최대한 증가시킬 것이 권장된다. ${ }^{11}$

어태치먼트가 충분한 의치의 유지력을 부여하지 못하 거나, 유지력의 소실이 빠르게 일어날 경우, 기능적 문제 뿐만 아니라 환자의 심리적인 불안감을 초래할 수 있다. 가공 바 어태치먼트 시스템은 자석이나 볼 등의 기타 어 태치먼트 시스템에 비하여 유지력이 좋고 여러 개의 임플 란트를 연결하여 저작력의 효과적인 분산을 가능하게 한 다는 장점이 있어 많이 사용되고 있는 시스템이다..$^{10}$ 재료 로는 전통적으로 비귀금속 합금이나 티타늄이 사용되어 왔다. 본 증례에서 제작한 가공 지르코니아 바는 기존의 재료에 비하여 심미적으로 우수하고 향상된 생체친화성 과 개선된 조직반응을 보인다는 장점이 있다. 금속 바 제 작시 시행하는 방전 가공 과정도 필요하지 않다. 뿐만 아 니라 $\mathrm{CAD} / \mathrm{CAM}$ 을 이용하여 제작할 수 있어 전통적인 방식의 기공과정에서 발생하는 오차를 줄이고, 쉽고 빠 르게 제작이 가능하다. ${ }^{12}$

피개의치의 바를 감싸는 슬리브와 구개 밴드에 사용 된 PEKK는 최근 각광받는 치과용 고분자 물질이다. 의 과영역에서 10 년 이상의 안정성과 임상실험상의 생체친 화성이 검증된 $\mathrm{PEEK}^{13}$ 보다 $80 \%$ 더 큰 강도를 나타내는 등 물성이 개선되어, 가철성 부분 의치의 주연결장치, 직 접유지장치, 이중관의치의 내외관 등 다양한 분야에서의 활용 가능성이 보고되고 있다. ${ }^{14}$ 무게는 금속보다 가볍 고, 증가된 마모저항성과 생체친화성, 부식저항성, 골과 유사한 탄성도를 띄는 것도 장점이다. ${ }^{15}$

초기 유지력과 함께 환자의 의치 사용에 따른 어태치먼
트의 유지력 소실은 의치 디자인시 고려해야하는 중요한 요소이다. 유지력의 소실은, 바 또는 슬리브 구조물의 파 절, 변형, 마모에 의해서 발생하는데, 본 증례의 경과 관 찰 기간 동안, 환자가 저작, 발음 등에 불편을 느낄 만큼 의 유지력 소실이 관찰되지 않았으며, 추후 유지력의 소 실 시, 저장된 $\mathrm{CAD}$ 파일을 활용하여 비교적 쉽게, 마모 된 슬리브를 대체할 수 있을 것으로 생각된다.

\section{결론}

본 증례에서는 상악 완전 무치악 환자에 임플란트를 6 개 식립하여, 바 어태치먼트를 활용한 임플란트 오버덴 쳐를 제작하였다. 가공 지르코니아 바와 PEKK 슬리브 를 $\mathrm{CAD} / \mathrm{CAM}$ 을 이용하여 제작하였다. 2 년간의 정기적 인 경과 관찰 결과, 심미적, 기능적으로 만족할 만한 결과 를 얻을 수 있었다.

\section{ORCID}

Jin-Seok Ju https://orcid.org/0000-0002-5697-7692

Jin-Hyun Cho https://orcid.org/0000-0002-2453-9372

Cheong-Hee Lee https://orcid.org/0000-0002-2005-0801

\section{References}

1. Zitzmann NU, Marinello CP. Treatment plan for restoring the edentulous maxilla with implantsupported restorations: removable overdenture versus fixed partial denture design. J Prosthet Dent 1999;82:188-96.

2. Zembic A, Wismeijer D. Patient-reported outcomes of maxillary implant-supported overdentures compared with conventional dentures. Clin Oral Implants Res 2014;25:441-50.

3. Sanna A, Nuytens P, Naert I, Quirynen M. Successful outcome of splinted implants supporting a 'planned' maxillary overdenture: a retrospective evaluation and comparison with fixed full dental restoration. Clin Oral Implants Res 2009;20:406-13.

4. Sadowsky SJ, Zitzmann NU. Protocols for the maxillary implant overdenture: a systematic review. Int J Oral Maxillofac Implants 2016;31 Suppl:s182-91.

5. Kim HY, Lee JY, Shin SW, Bryant SR. Attachment 
systems for mandibular implant overdentures: a systematic review. J Adv Prosthodont 2012;4:197203.

6. Stoumpis C, Kohal RJ. To splint or not to splint oral implants in the implant-supported overdenture therapy? A systematic literature review. J Oral Rehabil 2011;38:857-69.

7. Murray MD, Darvell BW. The evolution of the complete denture base. Theories of complete denture retention - a review. Part 1. Aust Dent J 1993; 38:216-9.

8. Petropoulos VC, Smith W, Kousvelari E. Comparison of retention and release periods for implant overdenture attachments. Int J Oral Maxillofac Implants 1997;12:176-85.

9. Sadowsky SJ. Treatment considerations for maxillary implant overdentures: a systematic review. J Prosthet Dent 2007;97:340-8.

10. van Kampen F, Cune M, van der Bilt A, Bosman F. Retention and postinsertion maintenance of barclip, ball and magnet attachments in mandibular implant overdenture treatment: an in vivo comparison after 3 months of function. Clin Oral Implants Res 2003;14:720-6.

11. Mericske-Stern RD, Taylor TD, Belser U. Management of the edentulous patient. Clin Oral Implants Res 2000;11:108-25.

12. Katsoulis J, Mericske-Stern R, Yates DM, Izutani N, Enkling N, Blatz MB. In vitro precision of fit of computer-aided design and computer-aided manufacturing titanium and zirconium dioxide bars. Dent Mater 2013;29:945-53.

13. Najeeb S, Zafar MS, Khurshid Z, Siddiqui F. Applications of polyetheretherketone (PEEK) in oral implantology and prosthodontics. J Prosthodont Res 2016;60:12-9.

14. Park C, Jun DJ, Park SW, Lim HP. Use of polyaryletherketone (PAEK) based polymer for implantsupported telescopic overdenture: a case report. J Adv Prosthodont 2017;9:74-6.

15. Passia N, Ghazal M, Kern M. Long-term retention behaviour of resin matrix attachment systems for overdentures. J Mech Behav Biomed Mater 2016; 57:88-94. 


\section{상악 무치악 환자에서 가공 지르코니아 바와 PEKK 슬리브를 이용한 임플란트 피개의치 증례}

주진석, 조진현, 이청희*

경북대학교 치의학전문대학원 치과보철학교실

본 증례에서는 상악 완전 무치악 환자에서 CAD/CAM으로 가공 지르코니아 바와 PEKK 슬리브를 제작하여, 바 어태 치먼트를 활용한 임플란트 지지형 피개의치로 수복하였다. 2년간의 정기적인 경과 관찰 결과 심미적, 기능적으로 만족할 만한 결과를 얻었기에 이를 보고하는 바이다.

(구강회복응용과학지 2017;33(4):307-13)

주요어: 상악 무치악; 지르코니아 바; PEKK; 임플란트 지지 피개의치 